\title{
La Tauromaquia en el imaginario social de Riobamba, "Ciudad Taurina del Ecuador"
}

\section{La Tauromaquia in the social imaginary of Riobamba, "Ciudad Taurina del Ecuador"}

José Miguel Ocaña Morales. ${ }^{1}$ \& Raúl Edison Lomas Badillo. ${ }^{2}$

\begin{abstract}
DOI: https://doi.org/10.33262/cienciadigital.v3i2.4.492

The present research work, tries to know which is the attitude of the new generations towards the Tauromaquia, activity considered like art and that was born as the result of the miscegenation for more than 500 years, but that has penetrated deep in the villagers that has become It is a fundamental part in the development of its popular festivities until it becomes rooted in our own culture, a circumstance that was ratified through a popular referendum held in 2011. However, there is a strong interference from foreign groups, mostly anti-bullfighting, they seek to influence their animalistic tendencies so that the bullfighting party disappears and with it the economic development that it generates. The new young people and citizens of the future, in order to recognize the city of Riobamba, as the Bullfighting Capital of Ecuador, it will be important to know what their attitude towards the development of this traditional "bullfight party" is.
\end{abstract}

Keywords: Bullfighting, Riobamba, culture, tradition, popular festival

\section{Resumen.}

El presente trabajo de investigación, pretende conocer cuál es la actitud de las nuevas generaciones hacía la tauromaquia, actividad considerada como arte y que naciera como resultado del mestizaje hace más de 500 años, pero que ha calado hondo en los lugareños que se ha convertido en parte primordial en el desarrollo de sus fiestas

\footnotetext{
${ }^{1}$ Universidad Nacional de Chimborazo, Facultad de Ciencias Políticas y Administrativas, Comunicación Social, Riobamba, Ecuador, mocana@unach.edu.ec

${ }^{2}$ Universidad Nacional de Chimborazo, Facultad de Ciencias Políticas y Administrativas, Comunicación Social, Riobamba, Ecuador, rlomas@unach.edu.ec
} 
populares, hasta constituirse en raigambre de nuestra propia cultura, circunstancia que fue ratificada a través de consulta popular realizada en el año 2011. Sin embargo, existe una corriente de grupos foráneos en su mayoría de anti-taurinos, que buscan influir con sus tendencias animalistas para que la fiesta taurina desaparezca y con ella el desarrollo económico que genera. Los nuevos jóvenes y ciudadanos del futuro, en la medida de reconocer a la ciudad de Riobamba, como la Capital Taurina del Ecuador, será importante conocer cuál es su actitud hacia el desarrollo de esta tradicional fiesta taurina.

Palabras claves: Tauromaquia, Riobamba, cultura, tradición, fiesta popular.

\section{Introducción}

Tauromaquia, expresión cultural o maltrato animal. Esta problemática motivo del presente estudio, conlleva a la indagación de premisas indispensables como lo es el origen de esta actividad taurina, la llegada al Ecuador, como se vive actualmente esta tradición en una nueva época de hibridación cultural, además el proceso que tiene estos eventos desde la crianza del toro, la significación de este ritual abarcando la comunicación verbal y no verbal, la identidad cultural, la cultura misma para luego proceder a la tauromaquia como imaginario colectivo y mediante esta el surgimiento de nuevos grupos con ideologías diferentes.

La voz tauromaquia, aparece en el diccionario de la (Real Academia Española [RAE], 2016) con dos acepciones distintas. La primera como arte de lidiar toros y la otra como obra o libro que habla de este arte. La lidia nace en el siglo XVIII, pero sus albores remontan al XV en España, al abandonar el toreo a caballo para realizarlo a pie (Todo Sobre España, 2009), siendo éste el punto de partida para la "fiesta brava", actividad que acarrea años de tradición y cultura que se ven reflejados en el fortalecimiento de las relaciones humanas y en la creación de obras artísticas de toda índole. Al principio no existían tercios, orden ni reglas en las cuadrillas. Es Francisco Romero el primer diestro que pone orden a la fiesta y el creador de la muleta tal y como hoy se la conoce.

La actividad taurina desde sus inicios siempre denotó aceptación mayoritaria, transformándose luego en un espectáculo público de gran aceptación e incluso algunas personas lo han convertido en parte de su vida profesional; pero también hay que destacar que otros sectores lo han concebido como un acto de violencia y maltrato animal; además de tener un fin netamente lucrativo que influencia comportamientos y conductas de violencia para quienes lo aprecian.

Las corridas de toros se llevan a cabo en diferentes lugares del mundo en donde ha trascendido en su cultura e identidad de las personas, entre ellas Portugal, Francia y en diversos países de Hispanoamérica, como México, Colombia, Perú, Venezuela, Panamá y Bolivia, en cada uno de ellos se ha convertido en una práctica 
históricamente reconocida y regulada por los ordenamientos jurídicos con la finalidad de mantener el orden público, garantizar los derechos de los espectadores, normar los establecimientos donde se realizan este tipo de espectáculos e incluso, reglamentar el propio festejo (Fernández de Gatta, 2010).

Ecuador no es la excepción, ya que su vasta historia de realización de festejos taurinos ha hecho que la legislación ecuatoriana, a lo largo de los años, haya adoptado un reconocimiento a la actividad taurina como una manifestación cultural del país (Somos Ecuador, 2012: 10). Es así que, en 1978, se expidió la Ley de Ejercicio Profesional de Toreros Nacionales (Decreto Supremo No. 2830, Registro Oficial 664) en cuyos considerandos se reconoce que la actividad taurina contribuye al desarrollo del país a través del turismo y que la necesidad de emisión de esa Ley radica en la importancia de coordinar la acción de las municipalidades en el control de los espectáculos taurinos y en la aplicación de las Ordenanzas Taurinas Municipales.

La capital de los ecuatorianos es una de las ciudades con mayor tradición taurina, arraigadas en 484 años desde su fundación y con una de las más importantes ferias en el ámbito sudamericano como es la de Jesús del Gran Poder. Cabe mencionar que Quito no fue la única ciudad en donde se realizaban festejos con toros durante la época colonial y republicana, ya que existen registros de que en Guayaquil y Baba existió una fuerte afición taurina (Jurado, 1996: 99). Así mismo, Ambato, Latacunga, Guaranda, Riobamba y otras ciudades del país, en especial de la Sierra.

Sin embargo, acogiendo los resultados de la consulta popular realizada en el año 2011 y ya que la feria "Jesús del Gran Poder" de Quito como principal feria taurina de Ecuador fue suspendida, el Gobierno Autónomo Descentralizado Municipal de Riobamba decidió declarar a esta ciudad como "Capital Taurina del Ecuador". La Ordenanza 011-201130 emitida por el Concejo Municipal de Riobamba tiene dentro de sus considerandos lo siguiente:

"El ineludible deber del poder público: fomentar, movilizar, conservar y preservar las riquezas artísticas y culturales, por constituir base indiscutible de la Historia Nacional y Regional, así como es un deber del Gobierno Autónomo Descentralizado Municipal de Riobamba proteger, mantener y preservar las tradiciones históricas, artísticas, culturales, deportivas y sociales de su cantón".

Además, el artículo 2 de la misma ordenanza establece el deber del gobierno municipal de "apoyar a las organizaciones taurinas en sus diversas manifestaciones, a las escuelas taurinas legalmente constituidas, como promotoras del Arte de la Tauromaquia en la difusión, promoción cultural y turística de las corridas y ferias de toros". 
Al respecto, se han generado ciertos criterios o ideas erróneas, primero que los toreros están dispuestos a correr peligro con el toro bravo, exponiendo su vida porque consideran una pasión que no tiene límites, por otro lado, los activistas no conocen toda la verdad acerca de la crianza de estos animales, cegados por proteger y cuidar la vida y dignidad del animal.

Para la ejecución del presente trabajo Mediante la investigación de campo con la aplicación de encuestas a la población y la ejecución de entrevistas a expertos se obtuvieron datos cualitativos y cuantitativos que permitieron llegar inferencias y conclusiones muy importantes acerca de esta construcción social llena de simbolismo, sentido y significación, basado en el legado cultural de occidente que con el pasar de los siglos se ha ido modificando el comportamiento y percepción de los habitantes de Riobamba, sobre estas prácticas y rituales de la fiesta taurina, que ahora también tiene componentes de la cultura Andina.

Este proyecto permitió conocer, analizar y comprender los diferentes aspectos históricos, sociales y culturales en los que se desarrolló la tauromaquia en nuestro país y principalmente en nuestra ciudad, rescatando de esta forma datos e información que por años han identificado un rasgo cultural de nuestro pueblo, y que hoy en día representa una problemática, o en mejores términos, una grave controversia, que incluso ha desembocado en la desaparición de esta fiesta tradicional en algunos lugares que antes eran reconocidos por este aspecto.

Además de analizar la influencia de los movimientos animalistas que manifiestan sus opiniones contrarias al maltrato animal porque considera a la tauromaquia como un espectáculo que atenta a la vida de otros seres vivos. Se analizó cómo influye esta nueva ideología de los activistas con ideas contrapuestas a la forma de pensamiento tradicional de la sociedad moderna, ya que la práctica taurina se convirtió en parte de la identidad cultural y se encuentra marcado en el imaginario colectivo de la población.

El desarrollo de la presente investigación, permitió identificar y analizar los diferentes abordajes y teorías referentes a la cultura y sus diferentes componentes y rituales que históricamente han formado parte de la tauromaquia, como una de las tradiciones y costumbres muy arraigadas a los pueblos latinoamericanos herederos de la colonización española.

Finalmente, podría decirse que la tauromaquia es un tema muy amplio que requiere ser observado y analizado, aún más aquí en Riobamba, siendo considerada como la primera ciudad en lo que respecta a este imaginario colectivo. Necesitándose, por ende, un estudio que se desglose desde el cuidado de los toros y su preparación para las corridas, hasta la contraposición directa entre los protestantes en contra del maltrato animal y quienes consideran a la tauromaquia como una tradición innata en la identidad ecuatoriana. 


\section{Marco Teórico}

Según (Rivadeneira, 1997), a simple vista, juntar los términos comunicación y cultura llevaría a incurrir en una tautología, sí, a simple vista, consideramos que la comunicación es inseparable de toda cultura y ésta no puede ser comprendida prescindiendo de los procesos de comunicación que le acompañan. Sin embargo, comunicación y cultura son dos universos insertos dentro de un macrocosmos que podríamos denominar la vida humana. Inseparables, interdependientes; el uno condición del otro, pero fenómenos de la vida humana con personalidad propia. Se puede definir la comunicación como el encuentro de un organismo viviente con su medio ambiente o entorno, cuando se entiende por dicho encuentro la recepción de informaciones sobre el mundo circundante y una reacción ante la información recibida. Esta fórmula abarca todas las posibilidades de "encuentro" del hombre con su medio ambiente físico, social y cultural; las relaciones humanas en sus diversas manifestaciones: económicas, políticas, deportivas, etc.; donde caben también niveles de relación con los productos de la tecnología: comunicación hombre máquina en la industria, en los procesos de aprendizaje y en los del entretenimiento. Incluye, asimismo, la relación del hombre con los medios masivos. Cubre el entorno variado y complejo que rodea al ser humano, esfera dentro de la cual actúa reaccionando objetos, hechos, funciones y relaciones son agentes emisores de mensajes para el receptor. Del entorno parten señales de variada índole que el hombre acomoda a sus necesidades.

Por su parte, (Rizo, 2008) menciona que, desde la Sociología y la Antropología, la mayoría de definiciones de cultura ponen el acento en las siguientes características: se basa en símbolos universales que nos ayudan a comunicarnos; se comparte entre los diferentes seres humanos; y, por último, es aprendida o adquirida. Como se puede observar, en estos rasgos está presente la comunicación bajo múltiples formas: una, la existencia de símbolos que ayudan a comunicarse a los seres humanos son construcciones culturales; otra, la cultura se transmite, y, por tanto, necesita de medios para su difusión; y, por último, el aprendizaje y la adquisición de cultura también implican formas comunicativas de mediación entre sujetos, o entre dispositivos y sujetos. En términos generales, se afirma que la cultura proporciona a las personas un marco de referencia cognoscitivo general para una comprensión de su mundo y el funcionamiento en el mismo. Esto les permite interactuar con otras personas y hacer predicciones de expectativas y acontecimientos.

Para (Bisbal, 1999), comunicación y cultura, dos categorías que constituyen hoy una pieza clave de la complejidad cultural que caracteriza e identifica al tiempo ahora. Un tiempo hecho a retazos, de hibridaciones, de nuevas formas de sentir la vida y vivirla. Requerimos demostrar la necesidad de asumir reflexiones, investigaciones y políticas que consideren a ese binomio como un tejido inseparable en nuestras relaciones, pero políticas culturales que tengan un enfoque amplio, abierto a los nuevos signos y nuevas maneras de encarar socialmente la relación cultural y comunicacional. Requerimos también una consideración 
seria sobre el proceso de integración simbólica que nuestros pueblos han tejido desde las vertientes y los cauces que han abierto las mediaciones comunicacionales impuestas, pero asumidas por las grandes industrias culturales de la música, del CD, de la radio, del cine, de la televisión.

Según (Molano, 2007), el concepto de identidad cultural encierra un sentido de pertenencia a un grupo social con el cual se comparten rasgos culturales, como costumbres, valores y creencias. La identidad no es un concepto fijo, sino que se recrea individual y colectivamente y se alimenta de forma continua de la influencia exterior. De acuerdo con estudios antropológicos y sociológicos, la identidad surge por diferenciación y como reafirmación frente al otro.

Para (Luna, 2007), es el sello característico de un pueblo, son sus costumbres y tradiciones, su comportamiento, su historia y geografía, su educación, su arte, sus conocimientos, sus logros, son sus idiomas y sus razas, es la energía que impulsa y permite el desarrollo de su sociedad y hace posible los cambios en la organización de su Nación y de su Estado. Identidad cultural también es alma, espíritu, amor por lo nuestro, meta común y acuerdo en lo fundamental para lograr el desarrollo. Es identificación plena con el pasado, el presente y el porvenir de una sociedad.

Según (Canclini, 1989), interpreta la hibridación cultural como una definición útil de las relaciones de significado que se han construido a través de la mezcla por lo tanto trasciende los procesos de mestizaje, criollización y similares. Tiene que ver con la influencia que ha ejercido la modernidad en donde lo tradicional y lo moderno se mezclan y en este caso los medios de comunicación tienen mucho que ver, también hace énfasis en la mirada transdisciplinaria para explicar el por qué coexisten culturas étnicas y nuevas tecnologías. En las actuales condiciones de globalización, encuentro cada vez mayores razones para emplear los conceptos de mestizaje e hibridación. Pero al intensificarse la interculturalidad migratoria, económica y mediática se ve que no hay solo fusión, cohesión, osmosis, sino confrontación y dialogo.

La hibridación, como proceso de intersección y transacciones, es lo que hace posible que la multiculturalidad evite lo que tiene de segregación y pueda convertirse en interculturalidad. Las políticas de hibridación pueden servir para trabajar democráticamente con las divergencias, para que la historia no se reduzca a guerras entre culturas. Podemos elegir vivir en estado de guerra o en estado de hibridación. Cada pueblo ha sufrido cambios en su estructura y se puede decir que es parte de su evolución, ya que debe adaptarse en este mundo universalizado para que puedan desarrollarse en estas nuevas eras, básicamente lo que hacen es mantener parte de sus naturalezas pasadas y acoger elementos futuros y seguir con su proceso de vida. 
Por su parte (Moebus, 2008), da a conocer que la noción de hibridación pretende ultrapasar las relaciones de oposición directa entre lo popular, lo culto y lo masivo; lo lúdico y lo racional; lo mítico y lo tecnológico; en una palabra, entre lo tradicional y lo moderno, volviéndose una noción que, basada en el principio de la interculturalidad y en la convivencia de temporalidades trans-históricas, niega la simplificación binaria entre pares de oposición conceptual como modelo de explicación de la realidad y de la dinámica social a favor de una perspectiva que reconoce en la fusión entre elementos aparentemente dispares la propia esencia de esa dinámica.

Nos dice (Gamero, 2007), la noción de lo imaginario en la sociedad contemporánea, está siendo revalorizada y comprendida a grandes rasgos como aquel sistema simbólico sobre el cual se apoya y a través del cual trabaja la imaginación, edificándose sobre la base de las experiencias de los agentes sociales, pero también sobre sus deseos, aspiraciones e intereses. El imaginario se establece de esta manera, como una matriz de conexiones entre diferentes elementos de la experiencia de los individuos, de manera colectiva, en donde las redes de ideas, imágenes, sentimientos, creencias y proyectos comunes están disponibles en un contorno sociocultural propiamente definido.

Nos dice (Cabrera, s.f.), básicamente las "significaciones imaginarias sociales" funcionan, en el sentido moderno y en relación con la sociedad, (1) instituyendo y creando, (2) manteniendo y justificando (legitimación, integración y consenso) y (3) cuestionando y criticando un orden social.

Las significaciones imaginarias sociales instituyen y crean un orden social a la vez que son instituidas y creadas por este mismo orden. La problemática de la institución y la creación social se encuentra inscrita en la tensión entre la determinación y la indeterminación sociocultural de estas significaciones. Entre la determinación social y la creación libre del espíritu se abre un campo que ha sido interpretado de múltiples maneras: determinación simple o compleja, causalidad y multicausalidad, influencia, correlación, afinidad electiva, entre otras propuestas.

Las significaciones imaginarias sociales también mantienen y justifican un orden social. Es lo que se conoce como los problemas de la legitimación, integración y consenso de una sociedad. Legitimación entendida como explicación, fuente de sentido y plausibilidad subjetiva; esto es, las significaciones sociales muestran, contrastan y ocultan, a la vez, una realidad social. Integración entendida como orientación y determinación de conductas; es decir, las significaciones sociales estimulan, permiten y prohíben la acción social porque la propia acción ya es simbólica o significativa en la medida en que es humana. Y consenso formulado como el acuerdo que permite y facilita el dominio del entorno social. De modo que las significaciones sociales permiten, a la vez, el dominio, adaptación y sometimiento de los individuos sociales a un orden anterior y exterior a ellos. Finalmente, las significaciones imaginarias sociales cuestionan un orden social a través de la crítica, la reforma y el cambio 
de una sociedad determinada. Tal cuestionamiento proviene de "otro lugar" o de "ningún lugar" como espacio de la esperanza o utopía.

Muchos consideran que la tauromaquia es un arte, aunque otras denuncian la práctica por la crueldad que implica hacia los animales. Los rituales y eventos vinculados a la tauromaquia son muy antiguos, remontándose a la Prehistoria.

Puede entenderse a la tauromaquia como toda la cultura que se desarrolla en torno a la actividad y que incluye vestimenta típica, el uso de ciertos instrumentos o armas, la cría de los animales, etc. (Pérez \& Merino, 2016).

En el análisis del imaginario, proceso en el que el sujeto puede identificar su imagen del "Yo" diferenciado del "Otro", esto es, definir el "Yo" a través del "Otro"; dicho imaginario llega a construir estereotipos, identidades y memorias colectivas, algunas de ellas enfrentadas.

La posguerra devolvía a la tauromaquia su carácter nobiliar medieval, asociándola a valores inmutables del carácter trágico español, fundamentado en un concepto de espíritu, idea de hispanidad, hoy desechado, sometiendo al torero y al público, antes protagonistas, al papel de simples espectadores del teatro de autoridades que desfilaba, como si de un paseíllo se tratase, cada tarde de toros. (Hernádez, 2016).

Es el caso del imaginario republicano y del imaginario franquista, el segundo, en la fiesta de los toros que como ya sabemos la cuna de esta fiesta es España, esta como elemento anquilosado representativo de la España franquista, pero acercándola a Ecuador específicamente a Riobamba esta fiesta esta impuesta por los colonizadores españoles a nuestros antecesores y adoptada como propia en la época colonial la ciudad hizo que esta fiesta sea parte de sus culturas. No es novedad que en los pueblos rurales de la serranía se dé esta fiesta ya que es parte de sus costumbres y por lo general la celebran junto a conmemoraciones o aniversarios de sus santos ya que también son muy religiosos y cabe recalcar que la misma al igual que las corridas de toros fue impuesta por los colonizadores a nuestros ancestros.

En la actualidad, el debate sobre la prohibición de la fiesta taurina abre viejas heridas y, en pleno siglo XXI, nos devuelve a los años treinta del siglo pasado, a aquella España dividida que hoy también es un mito, pues todo tiende a politizarse, la misma situación ocurre en nuestro país y como se puede explicar eso, si somos dos países diferentes.

No se trata de una excepción, otra excentricidad más de dos personajes cuanto menos peculiares, sino de un imaginario amputado por el franquismo, aquel que sometía en la plaza el juicio de los dirigentes a la voluntad popular, demostrando el valor de alguien capaz de enfrentarse a un toro de lidia a pie y no a caballo, como corresponde al vulgo. Esta interpretación de la fiesta era demasiado para un régimen asentado en valores aristocráticos 
y con pretensiones de hidalguía, es ahí que nace los anti taurinos como forma de rechazo al abuso y maltrata animal.

El espectáculo taurino, elemento característico de lo español, y el torero, capaz de poner de acuerdo por un instante a las dos Españas, se volvían del lado del régimen, tomando sus valores, olvidando...dicen que la muerte de Manolete supone la reconciliación en la posguerra. Más bien se supone otra de las manifestaciones de la imposición de la cultura de los vencedores sobre los vencidos. Esta parte de la fiesta es la que ha llegado, como estereotipo, a la actualidad. Pero en medio del debate hay quien se declara taurino y republicano. ¿Cómo es eso? Estas voces, aun tímidas, tratan de devolver a la fiesta su carácter popular, ajeno a los avatares de los políticos, pero por otro lado los anti taurinos tratan de desaparecer esta fiesta.

Según (Fernández, diversas opiniones sobre el origen de las actividades físicas en las que intervienen los toros, pero básicamente las podemos resumir en tres tendencias básicas, existiendo en cada una de ellas numerosos autores y hallazgos que pretenden apoyar su opinión; aunque tan solo mencionaremos alguno de ellos para intentar resumir su apreciación:

\section{a) Origen en el culto al toro como deidad.}

Por un lado, aquellos autores que consideran que estas actividades físicas estaban dirigidas a dar culto a un dios encarnado en la figura de un toro. En este sentido encontramos en los orígenes de la civilización occidental, varias deidades en las que sus leyendas están relacionadas con el culto al toro bravo como son: Mithra, Zeus y Europa, Pasifae y Minos.

\section{b) Origen en los ritos de ofrendas a los dioses.}

Por otro lado, aparecen multitud de actividades y ritos encaminados a utilizar al toro como elemento de sacrificio ritual a los dioses de ofrenda propiciatoria para obtener sus favores, especialmente relacionados desde los primeros tiempos con la fecundidad y la fertilidad, tanto por su bravura y fuerza, como por su abundancia en nuestra región (España); tal y como afirma (Casa, 1950) en su obra "Ritos agrarios: Folklore campesino español", quien considera que básicamente... "la lucha con el toro fue en sus orígenes un rito agreste."

\section{c) Origen en las ceremonias funerarias para aplacar a los difuntos.}

Por último, como actividad ritual funeraria que consiguiese aplacar a los "manes" difuntos. Encontramos muchas muestras de esta tendencia en la gran cantidad de toros o verracos iberos de piedra repartidos por los campos de toda España. Esta tendencia se conservaría en nuestro país hasta la época romana, en la que aparecen pruebas del carácter funerario de estos verracos de piedra, que para muchos historiadores también tenían funciones de delimitación 
de los terrenos de pastos, como en las inscripciones aparecidas en uno de los Toros de Guisando.

En la actualidad, la tauromaquia se redujo a la corrida de toros, espectáculo típicamente español en el que, desde hace siglos, un hombre provisto de una capa y una espada enfrenta, en la arena, a un toro enfurecido. No debemos confundir el toro doméstico con el toro de combate, descendiente directo de las antiguas razas salvajes. Un toro de lidia es un animal indómito, sumamente feroz y de fuerza extraordinaria; tiene el cuerpo brillante, la cabeza relativamente pequeña pero provista de astas punzantes, y un cuello poderoso. El hombre, durante la corrida, se empeñará con toda su fuerza y su astucia en debilitar los músculos de ese cuello para que el animal, obligado a bajar la cabeza, pueda recibir la estocada, de arriba hacia abajo y entre los omóplatos.

Esta fiesta no existiría si no existiese el toro bravo. El origen de esta raza de animales se la encuentra en el primitivo urus o uro que no habitó exclusivamente en España, pero sí es en este país donde encontró su mejor asentamiento.

Un importante precedente histórico se considera a los ejercicios de la caza del uro en la que se dieron los primeros enfrentamientos, en ellos, más importante que la propia fuerza física, eran la habilidad y destreza. Es quizás en estas tradiciones tan antiguas donde se puede encontrar el origen de las corridas de toros.

Los aficionados taurinos comprenden a las corridas de toros como una fusión entre el toro y el torero, y al mismo tiempo cada uno representa algo grandioso, como, por ejemplo, el torero representa a un héroe o una figura en esencia mitológica, mientras que el toro representa la bravura, la virilidad, la nobleza y la belleza.

\section{Marco legal}

(Ordoñez, 2009), da a conocer: Al ser el Ecuador un país que cuenta con una Constitución inclusiva, la Tauromaquia tiene su mayor fundamento y peso legal para ser protegida en dicho cuerpo normativo rector del sistema jurídico, puesto que se basa en varios derechos allí consagrados que no se pueden violentar de la noche a la mañana solamente por la intolerancia o disgusto de un grupo de personas, siendo el Estado el órgano encargado de garantizar y tutelar el fiel cumplimiento de dichos derechos.

La norma en la cual se fundamenta básicamente la Tauromaquia y el derecho de los taurinos a identificarse culturalmente con ella se consagra en $\operatorname{los}$ artículos 21, 22, 23 y 31 de la Constitución, los cuales mandan lo siguiente:

"Las personas tienen derecho a construir y mantener su propia identidad cultural, a decidir sobre su pertenencia a una o varias comunidades culturales y a expresar dichas elecciones; a la libertad estética; a conocer la memoria histórica de sus culturas y a acceder a su 
patrimonio cultural; a difundir sus propias expresiones culturales y tener acceso a expresiones culturales diversas."

"Las personas tienen derecho a desarrollar su capacidad creativa, al ejercicio digno y sostenido de las actividades culturales y artísticas, y a beneficiarse de la protección de los derechos morales y patrimoniales que les correspondan por las producciones científicas, literarias o artísticas de su autoría."

"Las personas tienen derecho a acceder y participar del espacio público como ámbito de deliberación, intercambio cultural, cohesión social y promoción de la igualdad en la diversidad. El derecho a difundir en espacio público las propias expresiones culturales se ejercerá sin más limitaciones que las que establezca la ley,25, con sujeción a los principios constitucionales."

"Las personas tienen derecho al disfrute pleno de la ciudad y de sus espacios públicos, bajo los principios de sustentabilidad, justicia social, respeto a las diferentes culturas urbanas y equilibrio entre lo urbano y lo rural."

(Toros Ecuador, 2011), Presenta un artículo en donde se menciona que las primeras noticias de ganado bravo en tierra ecuatoriana se encuentran en las crónicas del siglo XVII, cuando los religiosos jesuitas, mercedarios y dominicos trajeron ganado bravo a América para guardianes del ganado manso y de los cultivos. No es extraño, por esto, que la tradición nos cuente que los primeros toreros fueron los indios que debieron rápidamente aprender a sortear los bravos celadores. Los primeros toros que arribaron fueron de la casta navarra, una de las cinco castas fundacionales españolas.

Las referencias históricas sobre la realización de los primeros espectáculos taurinos en Quito se ubican en 1573, es decir, treinta y nueve años después de la fundación, sin embargo, existen noticias de que en 1549 se realizaron corridas de toros en Quito con motivo de las celebraciones de la Pascua.

En el mes Julio de 1898, se llevó a cabo en Quito la primera corrida de toros a la usanza española con 6 toros de la ganadería Pedregal ubicada en Machachi, propiedad de don Santiago Velasco lidiados con la participación de los matadores españoles Manuel Pomares, "Troni” y Manuel Vera "Mazzantinito".

La primera plaza de toros en Quito estaba ubicada en las inmediaciones del parque de el Ejido en 1.898, la segunda plaza de toros se construyó en 1.905 en Guangacalle actual Avenida Colombia, en el año de 1.917 se construyó la Plaza Belmonte inaugurada oficialmente en el año de 1.920, en el año de 1.930 se inaugura la Plaza de Toros Arenas. 


\section{Riobamba Capital Taurina del Ecuador}

Sobre la tauromaquia de la tierra, (Portal Taurino, 2014), menciona que la historia taurina en Riobamba comienza a partir de la creación de la plaza de toros "Monumental Raúl Dávalos" que es considerada como una de las más antiguas del Ecuador, tiene una capacidad para 7.800 personas y en ella se realizan también shows artístico musicales. Sus mayores espectáculos se realizan en las fiestas abrileñas y novembrinas. Inaugurada en 1952 por Morenito de Valencia y Lorenzo Pascual Belmonteño.

Diseñado y construido con graderíos de madera y una útil cubierta en los tendidos, la plaza albergaba en su primera etapa a 5 mil aficionados. En 1995 se emprendieron los trabajos de readecuación para ampliar su aforo a 10 mil personas y dotarla de funcionales instalaciones y belleza. La renovada plaza fue reinaugurada en 1997.

La Feria del Señor del Buen Suceso, se realiza anualmente durante las fiestas abrileñas de Riobamba, a propósito de la conmemoración de la Batalla de Tapi que selló la independencia de la ciudad el 21 de abril de 1822, ejemplar combate de caballería considerado como uno de las más brillantes jornadas militares que a la postre se constituiría en la antesala del triunfo definitivo logrado por los patriotas en Pichincha un mes más tarde (Aguilar, 2012).

En 1969 se crea la feria Señor del Buen Suceso, el matador Mariano Cruz y su apoderado Gonzalo Jácome "El brujo" ceden el primer trofeo los comerciantes devotos del Señor Del Buen Suceso, presidido por el Sr. Segundo Paula Moreno. En la primeria feria denominada "Señor Del Buen Suceso" se realiza una novillada mixta de feria, con 6 novillos-toros 6 de Santa Mónica para el cartel que presentaba a los rejoneadores (Cevallos, 2014).

Desde hace una década por este ruedo ha desfilado una interesante nómina de toreros en la que constan coletas de la talla de Rafael Camino, Manolo Sánchez, Víctor Méndez, Uceda Leal, Oscar Higares, Serafín Marín, David Fandila "El Fandi", Juan José Padilla acompañados de lo más sobresaliente de la torería local e importantes rejoneadores.

\section{Metodología}

La metodología para la realización de la presente investigación combina la perspectiva cuantitativa con la aplicación de encuestas dirigidas a los habitantes de la ciudad de Riobamba, con la finalidad de identificar el nivel de identidad cultural hacia la Tauromaquia e incidencia que esta posee en el imaginario colectivo de la sociedad moderna del territorio con influencia en el Ecuador; y la cualitativa con la aplicación de entrevistas a expertos y especialistas sobre el arte de la Tauromaquia, a través de las corridas taurinas que se desarrollan. El enfoque cuantitativo tiene una innegable potencia para el tratamiento de los datos más concretos; mientras que el cualitativo es una poderosa herramienta para entrar en 
la profundidad de los sentimientos (Behar Rivero,2008), actuando en procesos concretos de investigación, cada enfoque cubre las debilidades del otro, ratifica o niega sus resultados.

En este sentido, la metodología cualitativa, derivada y guiada por los resultados alcanzados en la etapa cuantitativa, permitió cruzar, cualificar, complementar y contrastar los datos cuantitativos con la información obtenida mediante las entrevistas de los expertos.

De acuerdo a Behar Rivero (2008) El método para la obtención del conocimiento denominado científico es un procedimiento riguroso, de orden lógico, cuyo propósito es demostrar el valor de la verdad de ciertos enunciados. Mediante la aplicación de este método se revisó y contrastó diferentes fuentes bibliográficas primarias relacionadas con el tema objeto de estudio.

También se aplicó el método histórico lógico para garantizar el significado y fiabilidad de los hechos pasados del arte de la Tauromaquia. El método histórico lógico nos ayudara a establecer las relaciones existentes entre los hechos acontecidos en el desarrollo de las ciencias ( Behar Rivero, 2008).

Así, se aplicaron 398 encuestas a personas de entre 15 y 60 años de edad, tras la obtención de una muestra representativa, de un universo de 151523 habitantes de ese segmento poblacional y posteriormente se aplicó entrevistas estructuradas a cuatro expertos y especialistas taurinos vinculados a la investigación. La información se consolidó en base al cuestionario y preguntas aplicadas a los encuestados y los resultados obtenidos, llegando a conclusiones muy decisorias sobre el fenómeno cultural de la Tauromaquia y su identidad cultural en el imaginario colectivo de la población de Riobamba.

\section{Resultados}

\section{a) Resultados de la encuesta y análisis estadístico}

En el desarrollo de la investigación para la recopilación de información sobre la Tauromaquia, se utilizaron las técnicas de la encuesta con la ciudadanía, partiendo de una muestra de 398 personas, el 68\% de los habitantes consultados testifican haber asistido a través del tiempo a las diferentes corridas taurinas por afición a la fiesta brava, como parte de las tradiciones culturales de la ciudad.

Con relación al apoyo de la ciudadanía a los eventos taurino que se desarrollan en la ciudad, el $51 \%$ de ellos están de acuerdo, ya que consideran que los eventos taurinos movilizan el turismo y dinamiza la economía; en tanto que el $49 \%$ demuestran su desacuerdo con la tradición taurina, debido al maltrato animal.

Con respecto a que los eventos taurinos sean considerados como arte y cultura, la mayoría de 
la sociedad Riobambeña se pronunció a favor con el 60\%, donde valoran estos eventos como un arte ya que el torero es un artista que es complementado por el toro. Además, mencionaron que estos eventos se han mercantilizado; sim embargo el $40 \%$, especialmente mujeres refieren que la Tauromaquia no constituiría un arte por el maltrato animal, ya que consideran que la matanza de los toros en las corridas taurinas, constituyen el sacrificio a seres vivos, demostrando así su oposición a la muerte del toro, pero al mismo tiempo evidenciando su apoyo y afición a la fiesta brava por ser parte de la cultura del pueblo.

Sobre las protestas anti taurinas las personas encuestadas se pronunciaron a favor y en contra; el 58\% no apoya esta corriente de grupos animalista opositores, por considerar que son grupos minúsculos que no reconocen las tradiciones culturales muy arraigadas al pueblo ecuatoriano y que no tienen conceptos claros sobre el verdadero arte, simbolismo, sentido y representación que constituye la Tauromaquia, donde se plasma los ritos culturales, uno de los más importantes que identifica a la etapa moderna.

En referencia con la eliminación de las fiestas taurinas, la posición de los encuestados está al mismo nivel entre quienes apoyan y quienes están en contra; la posición en contra de la eliminación, considera que las fiestas taurinas, constituyen una herencia cultural que identifica al pueblo, con sus costumbres, tradiciones, mitos, ritos, etc; y que además promueve el comercio en la ciudad atrayendo al turismo. Mientras que el sector que apoya la eliminación de la tradición taurina asevera que no les gusta el maltrato que se les da a los animales que participan en este evento taurino principalmente el toro.

Finalmente, sobre la identidad cultural con relación a la Tauromaquia y las corridas taurinas en la ciudad, el $51 \%$ de personas consultadas manifiestas que el arte del tereo y la fiesta brava constituye parte de la identidad y riqueza cultural heredada de la Conquista Española, que aún sigue viva. El 49\% de la población asevera que la tauromaquia no tiene ningún nivel de relación cultural con el pueblo ecuatoriano, ya que aluden que la fiesta taurina no es parte de la cultura Andina, sino más bien es una costumbre impuesta por los españoles durante la Colonia.

Sobre el imaginario colectivo de la Tauromaquia y las fiestas taurinas, la ciudadanía consultada en su gran mayoría, exterioriza su recuerdo de muchos eventos taurinos desarrollados en la ciudad y que constituyen parte de sus vivencias, historia y tradiciones que le identifican a Riobamba, como ciudad Taurina del Ecuador.

\section{b) Análisis de Expertos}

A través de la metodología cualitativa, derivada y guiada por los resultados alcanzados en la etapa cuantitativa, permitió cruzar, cualificar, complementar y contrastar los datos cuantitativos con la información obtenida mediante la aplicación de entrevistas a expertos y especialistas en la Tauromaquia, como es el caso de los periodistas taurinos: Gonzalo 
Estrella, Iván Arregui y el torero Orlando Congacha; a quienes les consultamos sobre el estado actual de la Tauromaquia en el territorio y en el Ecuador, así como el nivel de identidad cultural existente.

Para el periodista Estrella la Tauromaquia es un arte, donde se pone de relieve varios actos rituales con mucho simbolismo, sentido y significación, que liga al toro, al torero y a los aficionados que acuden voluntariamente a un evento taurino que mueve el turismo y dinamiza la economía local. Sin lugar a dudas, refiere Estrella, este tipo de espectáculos taurinos generan comunicación e interacción social, convirtiendo a las plazas de toros en espacios públicos de construcción social, con identidad y tradición cultural.

Iván Arregui, coincide con la opinión de Estrella, al considerar que la Tauromaquia constituye precisamente el arte del toreo como espectáculo de masas, que cuenta con mucho simbolismo que crea sentido en los aficionados a la tradición taurina que mueve el turismo y la economía de los pueblos católicos muy identificados con la cultura estética concebida de manera formal con los eventos taurinos organizados en las ciudades y en ascenso en la cultura popular a través de los toros de pueblo. Además, señala que todo esto tiene componentes de comunicación e interacción social vinculados a la identidad cultural de los habitantes.

Por su parte Orlando Congacha, torero en formación, sostiene que la Tauromaquia, es lo más sagrado que hay en su vida, más sagrado que su familia, que sus hijos; refiere que la tauromaquia simple y sencillamente es el arte que se lleva en las venas, y el arte que se demuestra a los demás. También, asegura que las tradiciones taurinas, constituyen esencia de la identidad cultural no solo de los habitantes de Riobamba, sino de varias ciudades del país y del mundo.

Adicionalmente los expertos consultados, coinciden en señalar que la tauromaquia como el arte del toreo, está en el imaginario colectivo de los habitantes de la ciudad, ya que es algo que los identifica por ser parte de las tradiciones más arraigadas en el pueblo, aunque haya sido una cultura traída desde España, luego se ha convertido en ícono de la identidad cultural ecuatoriana.

En relación con las manifestaciones anti-taurinas, los expertos argumentan que son pequeñas células que no tienen fuerza, enmarcadas en nuevas tendencias ideológicas opositoras que forman parte de la contracultura; puntualizan además que estos grupos anti-taurinos están movidos por situaciones políticas, que se oponen fundamentalmente al ingreso a espectáculos taurinos de menores de edad y a la muerte del toro. Sin embargo, dicen los expertos, la población de Riobamba ha dado muestra de ser una ciudad taurina por excelencia, tras haber ratificado su apoyo en el referéndum estatal. 


\section{Conclusiones}

- La Tauromaquia como imaginario colectivo cultural tiene más incidencia en los habitantes de edades comprendidas de 40 a 60 años, especialmente en los hombres.

- La Tauromaquia con sus diferentes rituales y prácticas taurinas se ha convertido en Riobamba y Ecuador en un verdadero ícono de identidad cultural, que promueve el turismo nacional e internacional y dinamiza la economía de las diferentes ciudades, donde el arte del toreo o "fiesta brava" cada vez tiene mayores niveles de aceptación en medio de movimientos juveniles anti-taurinos opositores a este tipo de espectáculos masivos.

- Riobamba, al ser reconocida actualmente como la "Capital Taurina" del Ecuador, posee diversos elementos y bienes patrimoniales materiales e inmateriales con mucho simbolismo y significación en aspectos de carácter taurino, como su infraestructura donde se destaca la reconocida Plaza de Toros Monumental "Raúl Dávalos", y en festividades está la feria taurina Señor del Buen Suceso.

- A causa de la larga historia que trae consigo la Tauromaquia en Riobamba, las diversas acepciones de la misma como imaginario colectivo se han ido consolidando en la cultura riobambeña.

- En cuanto a las manifestaciones anti-taurinas, no han prosperado mayormente en el ámbito local y nacional, ya que constituyen movimientos opositores a la tradición taurina que es parte de la cultura e identidad ecuatoriana, y más bien son vistos como movimientos de contracultura, que no tienen argumentos suficientes para tratar de eliminar esta fiesta cultural masiva que identifica a la gran mayoría de la población.

\section{Referencia Bibliográfica}

Aguilar, S. (23 de Marzo de 2012). Al Toro México. Obtenido de http://altoromexico.com/index.php?acc=noticiad\&id=11529

Bisbal, M. (1999). ARCHIVO PDF. Obtenido de Archivo PDF: http://www.ehu.eus/zer/hemeroteca/pdfs/zer10-03-bisbal.pdf

Boas, F. (1964). Cuestiones fundamentales de antropología. Buenos Aires: Solar y Librería Hachete S.A.

Cabrera, D. (s.f). Imaginario social, comunicación e identidad colectiva. Recuperado el 24 de 07 de 17, de http://www.portalcomunicacion.com/dialeg/paper/pdf/143_cabrera.pdf

Canclini, N. (1989). Cultura hibridas: estrategias para entrar y salir de la modernidad. México: Grijalbo. Obtenido de https://monoskop.org/images/7/75/Canclini_Nestor_Garcia_Culturas_hibridas.pdf 
Carpio, I. (s.f.). Archivo pdf. Obtenido de La crianza del toro bravo: http://www.colvema.org/pdf/9496criatoros.pdf

Casas, G. (1950). Ritos agrarios: Folklore campesino español. Madrid: Publicaciones 224.

Castoriadis, C. (1975). La institución imaginaria de la Sociedad. Buenos Aires: Tusquets.

Duarte, E. (2003). Por una epistemología de la comunicación. Sâo Paulo: Loyola.

Fajardo, L. (2009). Comunicación verbal. Bogota: Universidad Nacional de Colombia.

Fernández de Gatta, D. (2 de octubre de 2010). Toros y espectáculos públicos, potestad sancionadora. Madrid: 1078-1096. Obtenido de Toros y espectáculos públicos: la potestad sancionadora:

Recuperado

de:

http://www.taurologia.com/imagenes\%5Cfotosdeldia\%5C2809_ensayo_toros_

y_espectaculos_publicos_la_potestad_sancionadora.pdf

Fernández, J. (15 de Marzo de 2008). Orígenes de la Tauromaquia . Obtenido de Universidad Pablo de Olavide: http://www.cafyd.com/HistDeporte/htm/pdf/6-0.pdf

Gamero, M. (2007). La contemplación del mundo en la sociedad contemporánea en base a la construcción de imaginarios sociales. Recuperado el 29 de 07 de 2017, de https://www.um.es/tonosdigital/znum14/secciones/tritonos-1-imaginarios.htm

Hernández, A. (2014). Comunicación verbal y no verbal. México: Universidad Tecnológica de Izúcar de Matamoros.

Hernández, G. (08 de 09 de 2016). Franquismo y memoria en el cancionero de Sabina. Un ensayo de Purísima y oro. Recuperado el 19 de 07 de 2017, de https://cies.files.wordpress.com/2010/08/articulo-tauromaquia.pdf

Jurado, F. (1996). Quito ciudad de casta taurina. Quito, Ecuador. Editorial Delta.

Luna, J. (2007). Redacción popular. Recuperado el 11 de Mayo de 2017, de Identidad Cultural: http://www.redaccionpopular.com/articulo/identidad-cultural-que-es-y-paraque-sirve

Moebus, A. (28 de Noviembre de 2008). ARCHIVO PDF. Obtenido de Archivo PDF: http://www.scielo.org.mx/pdf/soc/v23n67/v23n67a3.pdf

Molano, O. (2007). Revista Opera. Recuperado el 11 de Mayo de 2017, de Identidad un concepto que evoluciona: http://www.redalyc.org/pdf/675/67500705.pdf

Moreno, V. (7 de Agosto de 2009). Somos Ecuador . Obtenido de Historia y Cultura Taurina: http://somosecuador.blogspot.com/2009/08/historia-y-cultura-taurina.html

Ordóñez, A. (2009). Archivo pdf. Obtenido de Documento de tesis: http://dspace.udla.edu.ec/bitstream/33000/574/1/UDLA-EC-TAB-2009-15.pdf 
Ortiz, E. (25 de Abril de 2017). Toros Ecuador. Obtenido de http://torosecuadorweb.blogspot.com/search?updated-max=2017-06-06T14:37:0007:00\&max-results $=4$

Osorio, F. (Diciembre de 2012). ARCHIVO PDF. Obtenido de Archivo PDF: http://oraloteca.unimagdalena.edu.co/wp-content/uploads/2012/12/LaSemi\%C3\%B3tica-de-la-Cultura-FranciscoOsorio.pdf

Pachala, J. (05 de Abril de 2016). Foros Ecuador. Obtenido de http://www.forosecuador.ec/forum/ecuador/cine-tv-radio-yespect\%C3\%A1culos/41255-feria-de-toros-se\%C3\%B1or-del-buen-suceso-riobamba2017

Pérez, J., \& MERINO, M. (12 de 04 de 2016). Definiciòn de tauromaquia. Recuperado el 19 de 07 de 2017, de http://definicion.de/tauromaquia/

Portal Taurino. (8 de Abril de 2014). Portal Tauriono . Obtenido de Wikipedia: https://es.wikipedia.org/wiki/Plaza_de_toros_Ra\%C3\%BAl_D\%C3\%A1valos_de_la_Ca lle

Rivadeneira, R. (1997). Comunicación y Cultura. Revista Ciencia y Cultura, 02.

Real Academia Española[RAE] (2016) Tauromaquia. rae.es. Recuperado de http://dle.rae.es/srv/search?m=30\&w=tauromaquia

Rizo, M. (2008). ARCHIVO PDF. Obtenido de Archivo PDF: http://sedici.unlp.edu.ar/bitstream/handle/10915/32064/Documento_completo.pdf?seque nce $=1$

Todo sobre España (2009). Toros: Origen Histórico. Recuperado de: https://www.red2000.com/spain/toros/1history.html

Toros Ecuador. (2011). Toros Ecuador. Obtenido de Los Toros Tradición Centenaria en Ecuador: http://www.torosecuador.com/?p=330

Villan, J. (2012). Tauromaquias.España: La esfera de los libros.

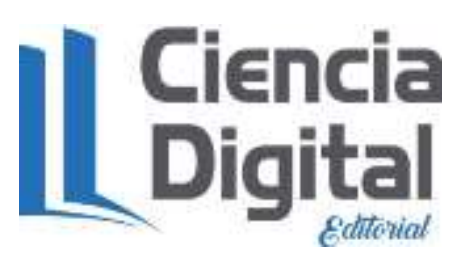


PARA CITAR EL ARTÍCULO INDEXADO.

Ocaña J. \& Lomas R., La Tauromaquia en el imaginario social de Riobamba, (2019) "Ciudad Taurina del Ecuador", Revista electrónica Ciencia Digital 3(2), 751-769. Recuperado desde: http://cienciadigital.org/revistacienciadigital2/index.php/CienciaDigital/article/view/492/11 $\underline{49}$

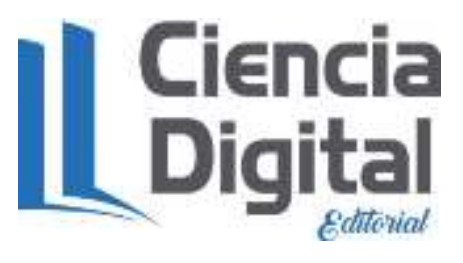

El artículo que se publica es de exclusiva responsabilidad de los autores y no necesariamente reflejan el pensamiento de la Revista Ciencia Digital.

El artículo queda en propiedad de la revista y, por tanto, su publicación parcial y/o total en otro medio tiene que ser autorizado por el director de la Revista Ciencia Digital.
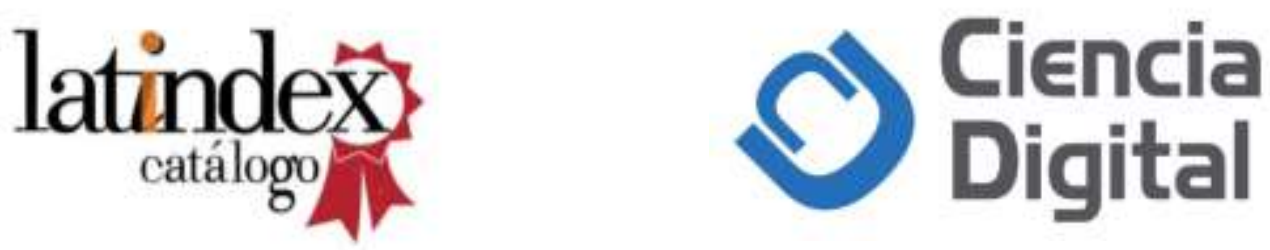